\title{
How to Valorize Biodiversity? Let's Go Hashing, Extracting, Filtering, Mining, Fishing
}

Authors

Affiliations
Quoc Tuan Do ${ }^{1}$, José L. Medina-Franco² ${ }^{2}$ Thomas Scior ${ }^{3}$, Philippe Bernard ${ }^{1}$

${ }^{1}$ Greenpharma S. A.S., Orléans, France

2 Facultad de Química, Departamento de Farmacia, Universidad Nacional Autónoma de México, Mexico City, Mexico

${ }^{3}$ Department of Pharmacy, Benemérita Universidad Autónoma de Puebla, Puebla, México

\author{
Key words \\ - chemogenomics \\ - data mining \\ - inverse docking \\ - profiling \\ - reverse pharmacognosy \\ - similarity searching
}

\section{Abstract \\ $\nabla$}

Nature was and still is a prolific source of inspiration in pharmacy, cosmetics, and agro-food industries for the discovery of bioactive products. Informatics is now present in most human activities. Research in natural products is no exception. In silico tools may help in numerous cases when studying natural substances: in pharmacognosy, to store and structure the large and increasing number of data, and to facilitate or accelerate the analysis of natural products in regards to traditional uses of natural resources; in drug discovery, to rationally design libraries for screening natural compound mimetics and identification of biological activities for natural products. Here we review different aspects of in silico approaches applied to the research and development of bioactive substances and give examples of using nature-inspiring power and ultimately valorize biodiversity.

\section{Abbreviations}

$\nabla$

$\begin{array}{ll}\text { received } & \text { July } 15,2014 \\ \text { revised } & \text { October } 21,2014\end{array}$

accepted January 9, 2015

\section{Bibliography}

Dol http://dx.doi.org/

10.1055/s-0034-1396314

Published online February 25 , 2015

Planta Med 2015; 81: 436-449

(c) Georg Thieme Verlag KG

Stuttgart · New York .

ISSN 0032-0943

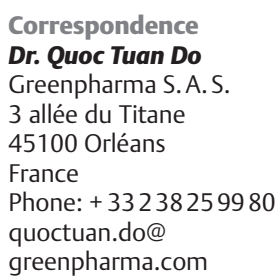

\section{Introduction}

$\nabla$

“'Biological diversity' or 'biodiversity' means the variability among living organisms from all sources including, inter alia, terrestrial, marine and other aquatic ecosystems and the ecological complexes of which they are a part; this includes di-
FAK: focal adhesion kinase

FEMA: Flavor and Extract Manufacturers Association

GRAS: generally recognized as safe

HERG K+: human ether-a-go-go-related gene potassium

HDAC1: $\quad$ histone deacetylase-1

HTS: high-throughput screening

MOE: molecular operating environment

NABATIVI: Novel Approaches to Bacterial Target Identification Validation and Inhibition

PCA: $\quad$ principle component analysis

PD: $\quad$ pharmacodynamic

PESD: $\quad$ properties encoded shape distributions

PK: $\quad$ pharmacokinetic

PLA2: $\quad$ phospholipase A2

PPAR: peroxisome proliferator-activated receptors

QSAR: quantitative structure-activity relationship

R\&D: $\quad$ research and development

SAR: $\quad$ structure-activity relationships

SPID: structure-promiscuity index difference

SVM: $\quad$ support vector machine

UFSR: ultrafast shape recognition

vHTS: virtual HTS

VLS: virtual library screening

ZINC: free database of commercially available compounds for virtual screening versity within species, between species and of ecosystems" [1]. Biodiversity is endangered by human activities, and its decline in some regions is exacerbated by climate changes. The extent of such modifications of the environment depends on complex criteria including geographical, environmental, political, and societal conditions $[2,3]$. 
This makes global protection policies, though necessary, very difficult to implement. Why and how to protect biodiversity? Some encouraging attempts have been made by regional actors to stimulate industry, nonprofit, and academic research in chemical and life sciences [4], national governments for biodiversity protection and societal issues [5] or, at a continental level such as the European FP7 project Marex composed of nine European Union countries and four developing countries, to explore the possible industrialization of bioactive substances from marine resources [6]. Ethical and utilitarian arguments are the common points from the numerous existing examples. Sustainable developments can be envisaged to valorize biodiversity (i.e., to estimate economic value, to highlight its value and/or to increase its value) in a variety of domains such as biofuels to replace fossil energy [7], materials, e.g., batteries made with emodin derivatives [8], biomimetics, i.e., nature as a source of inspiration to design new materials, processes, etc... [9], cosmetics [10], functional foods [11], or pharmacy [12].

Historically, natural products, e.g., plants, have been a source of food and medicine; as a matter of fact, in ancient civilizations, the two things are "interchangeable" according to Hippocrates. Therefore, a lot of knowledge was accumulated as evidenced by traditional Chinese medicine's so-called “Yellow Emperor's Inner Classic" or Dioscorides' "De Materia Medica", to cite a few. Nowadays, with the evolution of analytical techniques [13] and the fast development and advances of computers, the amount of data about natural products has grown drastically [14-16]. This allows for the emergence of new strategies to valorize the natural products, such as reverse pharmacognosy $[17,18]$, by working with natural flavor molecules $[19,20]$, by relating traditional medicine concepts to modern Western medicine pathologies [21], or by using ancestral knowledge as a starting point for scientific investigations [22]. In this review, we focus on the contributions of natural products in drug discovery aided by in silico techniques with a particular emphasis on the most frequently used approaches such as database mining, systematic screening using similarity searching and molecular docking, and inverse docking techniques.

\section{Drug Profiling during Research and Development \\ $\nabla$}

The term "drug profiling" is commonly used by academic groups, the pharmaceutical industry, and other institutions with drug research centers to define the experimental - and sometimes computational - measurements of physicochemical and pharmacokinetics properties, and the biological activities of their new drug candidates during R\&D processes [23].

\section{Pharmaceutical profiling}

Pharmaceutical profiling provides opportunities to deprioritize or eliminate undesirable molecules with unsuitable characteristics during the early stages of drug discovery. This practice has a great impact on the costs of $R \& D$ since unnecessarily passing along the R\&D pipeline a plethora of non-promising pharmaceutical agents is becoming even more labor intensive and resource demanding with each new R\&D stage reached [23]. During the error-prone attrition phase of discovery, when sorting out and reducing the amount of drug candidates, many research sites are establishing in-house drug candidate property guidelines based on scientifically sound concepts. In addition, thanks to their high-speed and low-budget nature, computational (in silico) tools have since been applied to complement or - on occasions - even substitute certain laboratory assays $[23,24]$. Those tasks where they have been proven to be really good at encompass the predicting of physicochemical properties and, to a lesser extend, pharmacokinetics for ADMET modeling. The latter simulates at a molecular level and numerically describes biological processes of drug absorption, body distribution, biotransformation (metabolism), excretion, elimination as well as toxic behavior. Nowadays, in vitro biological screening is the preferred tool for PK profiling [24]. It is undeniable in daily practice that a trade-off does exist between the fast, neat, and clean computational methods to calculate properties at the expense of data reliability and the by far more expensive and time-consuming techniques of experimental measurements in high-tech laboratories [24].

\section{Experimental and in silico profiling}

Many observed parameters can also be estimated with computer-based software $[25,26]$ ( 0 Table 2 in [27]). "Wet" HTS of compounds can be imitated by vHTS to identify promising candidates for further lead optimization and gives feedback about the identified single drug target ( $\odot$ Table 1 in [27]). If a vHTS does not exist, it can also be carried out against a pharmacophore model (substructures' interaction of the ligands) [28]. Computer programs used to predict the substrate selectivity and the regioselectivity (structures of metabolites, sites of metabolism on the substrates) are presented in the literature [29]. Recently, an alternative strategy to single target-based screening has been proposed by Fang using phenotypic profiling [30]. He combined the examination of the biological endpoints (drug effects) on a specific phenotypic behavior in cells, tissues, or whole animals. The advantage is that drug candidates can show their overall diseasemodifying action based on simultaneously hitting several hitherto unknown biomolecular targets in the cells [30]. Targeting more than one target (multitarget paradigm) has received attention as a feasible approach in the literature [31]. The latter must only be identified when the drug candidates are selected as hits. The logical workflow can be summarized as: (1) selection of disease with associated phenotypic endpoints (controlled symptoms); (2) phenotype profiling and endpoint(s) screening (by HTS); (3) intracellular, biomolecular target identification upon hitting; (4) compound library expansion to enrich it with more promising candidates; (5) in silico studies like vHTS (in parallel with HTS) and computational similarity analysis based on the chemical structures of the early hits for lead structure prioritization, ligand docking to target structures, lead compound optimization, VLS [27], QSAR [28] as well as docking studies to search for similar substances for compound library expansion; (6) drug safety profiles and tox screens; (7) preclinical studies; and, finally, (8) clinical trials (adapted from Fig. 1 in [30]).

\section{Biopharmaceutical profiling}

Historically, drug profiling focused on PD as the pharmacological endpoint with means to describe the molecular mode of action. Typical efforts embraced in vitro ligand binding assays, and ligand protein crystallography [24]. All too often the promising substance did not reveal its poor biopharmaceutical (formulation incompatibilities) or PK behavior (ADMET) in the initial stages of development but rather at the very end of the long road with the fatal consequences of losing time and money, or even worse with the complete loss of the candidate as a new drug in the pipeline [23]. Another paradigm has been changing during the last decade or so when shifting from late stage profiling to early stage 
Table 1 Empirical descriptors or patterns for a typical biopharmaceutical profile.

\section{Descriptors/parameters/patterns or features}

\section{$\mathrm{MW}<500$}

$\log \mathrm{P}<5$

Hydrogen bond donors (HBD) $<5$

Hydrogen bond acceptors (HBA) $<10$

Number of rotatable bonds (nrb) $<10$

Solubility $\log S$ at $\mathrm{pH} 6.5>10 \mathrm{mg} / \mathrm{L}$

Topological polar surface area (TPSA) $<140 \AA^{2}$

Aromatic rings $<4$

GI tract and BBB permeability decreases with a lower $\log D<0$

Water solubility and renal excretion increases with a lower $\log \mathrm{D}<0$

Water solubility and membrane permeability are "drug-like" in a range of $\log D$ between 0 to 3 units $(0<\log D<3)$

Water solubility is increased by polar groups, hydrogen bonding, or dissociation into ions or permanent ionization (cations, anions)

Potency increases with higher $\log \mathrm{D}>5$

Hepatic biotransformation by CYP450 increases with a higher $\log D>5$

Water solubility, oral absorption, and bioavailability tend to decrease with a higher $\log \mathrm{D}>5$

Water solubility increases, and lipophilicity and membrane permeability (by passive diffusion of a given drug) diminish

Esters and other prodrug solutions increase lipophilicity if the acidic drug is too hydrophilic

\section{References}

[33]

[33]

[33]

[33]

[34-36]

[32]

$[37,38]$

[39]

[40]

[40]

[40]

[40]

[40]

[40]

[40]

[40]

[40]

Table 2 Natural product database.

\begin{tabular}{|c|c|c|c|c|}
\hline Database name & Accessibility & Data types & Advantages & Drawbacks \\
\hline AfroDB [60] & $\begin{array}{l}\text { Freely accessible from the } \\
\text { supplementary information } \\
\text { of [60] }\end{array}$ & $\begin{array}{l}1000 \text { Compounds; physico- } \\
\text { chemical data and ADMET } \\
\text { properties }\end{array}$ & $\begin{array}{l}\text { Comprehensive predicted } \\
\text { data }\end{array}$ & No data on plants \\
\hline Chem NetBase [62] & $\begin{array}{l}\text { Searches are free; results } \\
\text { browsing under license } \\
\text { http://dnp.chemnetbase. } \\
\text { com }\end{array}$ & 170000 Natural compounds & $\begin{array}{l}\text { Very comprehensive; fre- } \\
\text { quently updated }\end{array}$ & $\begin{array}{l}\text { Lack of organism data; com- } \\
\text { mercial database }\end{array}$ \\
\hline Dr Duke's database [63] & $\begin{array}{l}\text { Freely accessible http:// } \\
\text { www.ars-grin.gov/duke }\end{array}$ & $\begin{array}{l}7500 \text { Molecules, } 2000 \text { orga- } \\
\text { nisms, } 2200 \text { traditional uses; } \\
\text { biological activities }\end{array}$ & $\begin{array}{l}\text { Many ways to query the da- } \\
\text { tabase; huge amount of data }\end{array}$ & $\begin{array}{l}\text { Lack of molecule data (struc- } \\
\text { tures, etc.); not updated } \\
\text { since } 1998\end{array}$ \\
\hline GPDB [10] & $\begin{array}{l}\text { Greenpharma internal } \\
\text { search }\end{array}$ & $\begin{array}{l}140000 \text { Compounds, } \\
160000 \text { organisms, } 4360 \\
\text { targets, } 10000 \text { activities, } \\
1000 \text { traditional uses }\end{array}$ & $\begin{array}{l}\text { Rich query system; structural } \\
\text { searches; numerous links be- } \\
\text { tween data }\end{array}$ & $\begin{array}{l}\text { Lack of data, but very fre- } \\
\text { quently updated }\end{array}$ \\
\hline KNApSAcK [64] & $\begin{array}{l}\text { Freely accessible } \\
\text { http://kanaya.naist.jp/ } \\
\text { knapsack_jsp/top.html }\end{array}$ & $\begin{array}{l}51000 \text { Molecules, } 22000 \text { or- } \\
\text { ganisms, } 110000 \text { metabo- } \\
\text { lite/species pairs }\end{array}$ & $\begin{array}{l}\text { Frequently updated; query } \\
\text { to database can be imple- } \\
\text { mented in software }\end{array}$ & No structural search \\
\hline Napr alert [65] & $\begin{array}{l}\text { Searches are free, but pay per } \\
\text { view for results report http:// } \\
\text { www.napralert.org }\end{array}$ & $\begin{array}{l}200000 \text { Publications anno- } \\
\text { tated; organisms; molecules; } \\
\text { biological activities; ethno- } \\
\text { pharmacological data }\end{array}$ & $\begin{array}{l}\text { Very comprehensive; fre- } \\
\text { quently updated }\end{array}$ & $\begin{array}{l}\text { Lack of molecule data; com- } \\
\text { mercial database; lack of } \\
\text { flexibility in results presenta- } \\
\text { tion }\end{array}$ \\
\hline Pfaf [66] & $\begin{array}{l}\text { Freely accessible http:// } \\
\text { www.pfaf.org }\end{array}$ & $\begin{array}{l}7000 \text { Plants; traditional uses; } \\
\text { medical and edible quality } \\
\text { scores }\end{array}$ & $\begin{array}{l}\text { Seldom used and original } \\
\text { plants; highly suited to RPG }\end{array}$ & No molecule data \\
\hline Supernatural [67] & $\begin{array}{l}\text { Freely accessible http:// } \\
\text { bioinformatics.charite.de/ } \\
\text { supernatural/ }\end{array}$ & $\begin{array}{l}46000 \text { Natural compounds; } \\
\text { molecule characteristics; } \\
\text { supplier data }\end{array}$ & Similarity searches & No organism data \\
\hline TCM-ID [68] & $\begin{array}{l}\text { Freely accessible http://bidd. } \\
\text { nus.edu.sg/group/TCMsite/ } \\
\text { Default.aspx }\end{array}$ & $\begin{array}{l}12000 \text { Compounds; } 1100 \\
\text { plants; } 1200 \text { TCM formula }\end{array}$ & $\begin{array}{l}\text { Interesting relation with } \\
\text { TCM-molecules }\end{array}$ & Cannot be exported \\
\hline UNPD [69] & $\begin{array}{l}\text { Free accessible http:// } \\
\text { pkuxxj.pku.edu.cn/UNPD }\end{array}$ & 200000 Compounds & $\begin{array}{l}\text { Largest noncommercial and } \\
\text { freely available database for } \\
\text { natural products }\end{array}$ & No data on organisms \\
\hline
\end{tabular}

intervention. The ultimate goal of pharmaceutical profiling is to predict potential drawbacks concerning critical issues of PD and PK as well as the development of trial dosage forms or final delivery systems as early as possible and to evaluate drug usage and security risks in general [23].
Medicinal chemistry textbooks contain some popular rules of thumb like the empiric replacement patterns for chemical groups known as biostereo-isomerism, the traffic light scheme for Lobel's “Oral PhysChem Score" [32] or "Lipinski's rule of five" [33], which can be embedded in drug-likeness screens or biopharmaceutical profiling efforts ( Table $\mathbf{1}$ ). 


\section{Computer-based profiling}

Recently, a theoretical study demonstrated the toxicological characterization of a series of chemicals with cheminformatics. To this end, the cytotoxicity profile was estimated on the basis of structural molecular fragments to identify several moieties that can be regarded as bearing cell toxicity (cytotoxicophores) [41]. The detection of fragments with proven or alleged toxic properties, so-called toxicophores, can be carried out on the Web-based server Ochem, (https://ochem.eu/) via a link to ToxAlerts. The server also provides QSAR modeling. Another helpful, almost all-in-one solution is Vega ZZ for 3D model generation, biomolecules, manual docking, empirical molecular mechanics force field calculations or semiempirical quantum mechanics, to list only a few features [42]. The use is free for public universities and not-for-profit research institutes. As a general rule for the software novice, computed values can be used with confidence if the compound lies within the applicability domain (scope) of a program $[43,44]$. Software algorithms looking up databases or parameter sets when applying empirical equations are more susceptible than first principle $a b$ initio methods. The latter are not foolproof either and can fail, too, if the underlying theory does not reflect natural processes. In general, conventional small organic molecules are more likely to be in the applicability or "calibration" range. Other structures fall short of expectations because they possess noncanonical electronic constellations, like carbamoyl, azid, nitro, sulfon, and metal organic groups or they are hydrazones, thioesters, etc. Sometimes, electronic, mesomeric effects depend on the conformation (between bridged aryl rings), and $\mathrm{pK}_{\mathrm{a}}$ predictions tend to fail. Recent approaches successfully applied classification models for drug profiling in combination with public databases (PubChem [27,45], AntiMarin database [46]). The success was documented for some modeled activities that could be found in the literature and thereby confirmed [47].

Newman and Cragg have reviewed the contributions of natural products as sources of new drugs for three decades from 1981 to $2010[12,48,49]$. They are still important because they provide the final entity or are starting points in drug discovery (mimetics, derivatives, botanicals, etc.), particularly in oncology and infection domains. To date, only one de novo drug obtained from combinatorial chemistry has been approved during the reviewed period. What makes natural products so successful? What lessons can the medicinal chemist learn from natural products and their properties?

In the pharmaceutical industry the attrition rate remains very high [50], particularly at the later stage of expensive clinical trials. Therefore a "fail early, fail cheap" paradigm represents an attractive strategy. Many investigators have tried to capture the essence of existing drugs to extrapolate physicochemical criteria with the ease of implementation along the drug discovery workflow. O Table 1 lists examples of the different empirical descriptors derived from statistical mining of drug databases. Thanks to their numerical nature they can be used as prefilters in virtual library screenings, QSAR studies [28,51], or in compound selection in general. However, one must be cautious about their use. For instance, Lipinski's rule of five of "drug likeness" (oral delivery and passive absorption mechanisms) [33], though widely used, is not applicable to natural products and does screen out many drugs derived from natural products. Keller et al. [52] hypothesized that natural compounds may have evolved over millennia to take advantage of active transport or gained specific conformations suited to passive transport. For Kellenberger et al., the reason of natural drugs may be the similarity of interactions of natural products with biosynthetic enzymes and therapeutic targets [53]. As a large number of drugs are derived from natural sources, we see an overlap of the drug chemical space and the natural compound space [54]. Indeed, several authors have advocated mimicking certain physicochemical profiles of natural compounds to synthesize compounds that are more diverse and biologically relevant [54-57], e.g., a reduced number of nitrogen atoms or aromatic rings, the presence of nonaromatic, polycyclic core structures, etc.

HTS assays can be perturbed by certain chemical features, generating a false positive. Rishton surveyed such reactive functional groups in [58]; among them some can be frequently found in active natural compounds and drugs, such as aldehydes, aliphatic esters and ketones, epoxides, 1,2-dicarbonyl compounds (tanshinones), Michael acceptors (chalcones), peroxides (artemisin derivatives), and disulfides (glutathione disulfides). Some natural compounds may therefore be filtered out because they are not suitable for HTS.

\section{Data Mining}

\section{$\nabla$}

The scientific literature search, storing, and exploitation are imperative and have come to terms with data mining in the modern ages of electronic information technologies. Information that is produced and kept in-house (corporate data sources) is not publicly available. Proprietary data can be used by costumers on a commercial basis, while other sources lay open on the Internet (free web services). Helpful web sites to assist the profiling phases are scientific journals, patents, and bioinformatics services dealing with genomics, proteomics, and metabolomics. The literature survey compiles relevant data on comparative or disease-associated genetics, pharmacogenetics, pharmacodynamics, pharmacokinetics, metabolic and cellular signaling pathways, in vitro and ex-vivo (cell based) pathophysiological models, etc. [59]. Databases on traditional usage of natural substances are also booming with descriptions from the organisms to the molecules with folk uses, biological data, and predicted properties.

Ethnopharmacology data offers valuable "clinical" observations that can guide the drug discovery process (see $\boldsymbol{O}$ Table $\mathbf{2}$ for examples of database). Bernard et al. [19] gathered a list of plants used in several populations of Latin America in cases of insect stings or snakebites to find new anti-inflammatory agents targeting PLA2. Extracts of plants used by several populations for these ailments were tested in priority on PLA2. By searching for compounds that were common to the active extracts in their inhouse database, the authors could narrow the possible candidates and perform docking on PLA2 to retrieve betulin and betulinic acid as potent inhibitors of PLA2. This prediction was further validated by in vitro binding tests. This work demonstrated the usefulness of computer-based analysis of ancestral knowledge to guide and accelerate the modern drug discovery process. Moreover, it also enabled experiments to prove some intuitive relations between folk medicine concepts (insect stings) and modern medicine pathology (inflammation). Rollinger et al. [21] have demonstrated the efficiency on combining in silico techniques with ethnopharmacological knowledge. Molecules from plants listed in Dioscorides' "De Materia Medica" as having "anti-inflammatory properties" were screened on structure-based pharmacophore models of COX 1 and 2 . The hit rate using this procedure was about $100 \%$ higher compared to the same virtual screening 
but on molecules from databases comprising marketed and development drug substances or natural compounds.

More recently, an interesting initiative by Ntie-Kang et al. [60] offered access to a database of more than 1000 natural compounds isolated from African medicinal plants, called AfroDB. The authors calculated numerous descriptors of drug-, lead-, and fragment-likeness and ADMET. They predicted the following ADMET properties: bioavailability, BBB penetration, dermal penetration, plasma-protein binding, metabolism, and blockage of the HERG $\mathrm{K}$ + channel. These parameters were also made available to the research community to help with compound selection, comparison, and virtual screening. The p-ANAPL library [61] containing most of the compounds of AfroDB was supplied upon request to the authors for in vitro validation. This type of initiative will no doubt encourage drug discovery from African plants and collaborations to valorize these resources.

The wealth of structural data on natural compounds allows investigators to compare drugs with natural compounds, and vice versa, to derive SAR and, subsequently, to deduce putative biological activities. Similarity searching is a fertile approach in drug discovery.

\section{Similarity Searching}

$\nabla$

Similarity-based screening or similarity searching is a typical ligand-based approach that can be conducted without prior knowledge of the 3D structure of the target. This approach is based on the notion that similar compounds have similar activity [70]. Remarkable exceptions to this concept are the "activity cliffs", i.e., similar compounds with an unexpectedly high activity difference. The interested reader is referred to reviews that address in detail the role of activity cliffs in medicinal chemistry and elaborate on the computational approaches to identify them $[71,72]$. Similar to other computational screening efforts, similarity searching should be part of an iterative process that involves the prediction, experimental testing of selected compounds, and design of new chemical data sets based on the structure of the experimental hits. Also, if enough information of the system is available, e.g., 3D coordinates of the target, similarity searching should be combined with other ligand-based and/or structurebased methods. The selection of a particular approach or set of methods depends on the aim of the project, the information of the system, and the computational resources available. Moreover, one needs to consider the inherent limitations of each step involved and the associated computational cost.

In natural products research, the combination of computational approaches has been emphasized by Yue et al., who have recently discussed progress on the target profiling of natural products using experimental (genomics and proteomics) and computational approaches [73]. In that review, Yue et al. emphasized the convenience of integrating various methods, such as inverse docking (docking compounds across different targets), mapping ligandtarget profiling space, and network analysis.

Similarity searching can be combined with other current major strategies in drug discovery such as drug repurposing. A recent example of this successful synergy is the similarity searching of a database of approved drugs that led to the identification of olsalazine, an anti-inflammatory drug approved for the treatment of ulcerative colitis, as a novel DNA hypomethylating agent [74]. Comprehensive reviews of virtual screening that cover methods, successful applications, pitfalls, and workarounds are published elsewhere [75-78]. Advances in the progress in the virtual screening of NPs have also been presented [79-85].

Any similarity searching involves several essential components, which are briefly outlined below.

A) One or more query or reference molecules that are compared against a molecular data set. The reference molecule is typically a chemical structure that can be represented in 2D or 3D. In general, in similarity searching, a notable advantage of 2D over 3D approaches is computational speed since most 2D methods (with the exception of those using chemical graphs) do not require costly structure alignments. In contrast, many but not all 3D methods require such alignments [86]. Moreover, 3D approaches have to deal with the conformational flexibility of the molecules, which, in many instances, give rise to multiple low-energy conformers. Diverse solutions have been proposed to alleviate this problem [87]. Currently, most 3D similarity searching studies use a single low-energy conformer (usually the global minimum or other representative 3D conformation). This, in any case, raises the question if such a conformation is biologically significant [88].

The performance of 2D and 3D similarity approaches has been compared directly in a number of applications, including virtual screening [89-92]. Since 3D similarity searching should incorporate, at least in principle, more accurate features than 2D methods, it would be expected that the results obtained from 3D methods should be more reliable than those obtained by 2D methods. However, in many instances, 2D approaches have outperformed 3Dapproaches, although it has been noted that this superiority is somewhat case-dependent [92].

Depending on both the data set and the biological activity, it is feasible that one or more reference compounds are associated with activity cliffs. In other words, they may be an "activity cliff generator" (defined as a molecular structure that has a high probability of forming an activity cliff with molecules tested in the same biological assay) [93]. Since, as discussed above, activity cliffs are exceptions to the similarity principle and lead to misleading results in similarity searching, it has been proposed that activity cliff generators be identified and removed from the data sets before selecting the reference compounds. In addition, the removal of activity cliff generators has been proposed as a general approach to be employed before developing predictive models, such as those obtained with traditional QSAR or other machine learning algorithms based on the similarity property principle [94].

B) Another element in similarity searching is the compound database. Compound databases have been reviewed elsewhere, including collections of natural products in the public domain [95]. A current trend in screening libraries for drug discovery is to balance chemical novelty with confined chemical space [96]. In this context, natural product databases (and natural product derivatives) are excellent sources for virtual screening as they expand the currently known medicinal chemistry space [97]. The "expansion" is associated in part with molecular complexity. This feature makes natural product databases attractive to identify compounds with a high selectivity towards molecular targets (including a target family) and can be ideal resources to identify "master key" compounds that selectively bind to a series of targets in order to yield a desired clinical effect [31]. Examples of specific and appealing regions in chemical space covered by databases of natural products include peptides and macrocycles [96]. C) A third and critical component in similarity searching is chemical representation, which is at the core of virtually any chemoin- 
Table 3 Representative and recent studies using similarity searching to uncover bioactive compounds in natural products and related compounds.

\begin{abstract}
Study
Sequential virtual screening of ZINC natural compounds identifies five compounds as PPAR- $y$ partial agonists.

Sequential docking-based virtual screening followed by similarity searching to select promising inhibitors of DNMT1 in two natural products collections.

Searching of GRAS compounds to uncover compounds similar to approved antidepressants. Identification of nonanoic acid and 2decenoic acid (similar to valproic acid) as inhibitors of HDAC1.

Structural comparison of the FEMA GRAS list with analgesics and with compounds used as satiety agents.

Similarity searching to identify compounds in a compiled database of phytochemicals with activity against a protein involved in the colon cancer pathway or a colon cancer drug target.
\end{abstract}

\begin{abstract}
Similarity searching method used
Electrostatic and fingerprint-based similarity analysis combined with ADMET and structure-based filtering.

Fingerprint-based similarity searching using MACCS keys and the similarity coefficients Tanimoto and Tanimoto-substructure.

Fingerprint-based similarity searching with MACCS keys/Tanimoto.

Comparison based on physicochemical properties and seven structural representations obtained from three different software programs.

Text mining in PubMed abstracts led to the collection of more than 20000 diverse chemical structures present in the human diet. Authors systematically explore their numerous targets using chemoinformatics methods.
\end{abstract}

Ref. formatics application. However, chemical representation is not an easy task because similarity is a subjective concept. It is largely known that chemical space (including similarity searching) depends heavily on molecular representation. It has been shown that if one uses different representations in similarity searching, the hit compounds (the most similar molecules to the query) will likely be different [98]. In actual applications of similarity searching, and molecular similarity analysis in general, a number of different types of representations are used. The information contained in the representations is usually in the form of molecular or chemical features called descriptors that are obtained from the structural and chemical properties of molecules. Descriptors are nominally classified as 1D, 2D, or 3D. 1D descriptors are commonly related to whole molecule properties such as molecular weight, $\log$, solubility, number of hydrogen bond donors, number of rotatable bonds, etc. 2D descriptors are associated with the topological structure of molecules as typically depicted in chemists' drawings. This type of representation shows the atoms, the bonds connecting them, and in some cases includes stereochemical features, but they do not explicitly depict the 3D structures of molecules. 3D descriptors, as their name implies, are associated with the 3D structures of molecules [88]. Todeschini and Consonni have assembled a comprehensive list of the descriptors used in chemical informatic applications [99].

Despite the fact that many descriptors are available, it is highly unlikely that a single representation and set of descriptors will capture all of the many different aspects of molecular and chemical information [88]. Therefore, in order to reduce the impact of the dependence of chemical representation in similarity searching, it has been proposed to use several methods and then combine the solutions. This is called "data fusion", and the group of Willet is a pioneer in this field [100]. A recent exhaustive study conducted by Holliday et al. [101] provides strong evidence that suggests that fusion-based approaches to similarity searching yield improved results over single-search-based similarity methods. Following a similar approach, the use of several molecular representations and then the combination of such representations has been implemented in different areas of chemoinformatics, including activity landscape modeling. In the latter, the term "consensus activity cliffs" have been proposed [102].

D) A fourth component of similarity-based virtual screening is a similarity measure which, in turn, depends on three elements: (1) the representation used to encode the desired molecular and chemical information, (2) whether and how much information is weighted, and (3) the similarity function, also called the similarity coefficient, that maps the set of ordered pairs of representations onto the unit interval of the real line [88].

Using the components of similarity searching outlined above, different groups have been using similarity searching alone or in combination with other computational approaches to uncover bioactive compounds from natural products. Examples of recent investigations are summarized in 0 Table 3 and described in the following paragraphs.

Guasch et al. used a combination of computational methods to identify five PPAR- $\gamma$ or PPARG [107] partial agonists from a compound collection with more than 89000 natural products and natural product derivatives from ZINC [108]. The authors of that work implemented a sequential or cascade virtual screening approach using a set of ADMET filters, structure-based pharmacophore screening, molecular docking, electrostatic, and fingerprint-based similarity analysis. A total of ten compounds with different chemical scaffolds were selected for experimental validation using in vitro assays. All five compounds were confirmed as PPAR- $\gamma$ partial agonists [108].

Also in a combined approach, Medina-Franco and Yoo implemented a sequential computational screening of five compound libraries to identify candidate compounds for testing as potential inhibitors of DNMT1. The reference molecule was a known DNMT inhibitor recently identified from HTS whose chemical structure was made publicly available in PubChem. The compound databases screened included two collections of natural products, a DNMT-focused library, a general screening collection, and a set of approved drugs. Similarity searching was performed using the widely used MACCS keys (166 bits) as implemented in MOE. The molecular similarity was computed using two measures, Tanimoto and Tanimoto-substructure. Of note is that Tanimotosubstructure takes into account the putative different sizes of the query molecule and the compounds in the databases screened. Compounds selected from similarity searching were subject to docking with a crystallographic structure of human DNMT1 using a validated docking protocol. At least 108 molecules with promising DNMT1 inhibitory activity were identified. The chemical structures of the computational hits were disclosed to encourage the research community working on epigenetics to experimentally test the enzymatic and demethylating activity in vivo [104]. 
Feng et al. [109] used chemoinformatics analysis based on Lipinski's rule-of-five, ChemGPS-NP [110] principal component analysis, and chemical clustering to compare a set of antitrypanosomal marine natural products with approved drugs to prioritize products with a similar profile as the reference drugs.

GRAS compounds are largely comprised of natural products. A recent and notable application of similarity searching of GRAS compounds for bioactive compounds is represented by the work of Martinez-Mayorga et al. In that work, the authors searched for similar structures to approved antidepressant drugs in the food flavoring components in the FEMA GRAS list [19]. The virtual screening was conducted using fingerprint-based similarity searching with the MACCS keys and the Tanimoto coefficient. Hit compounds in the FEMA GRAS list were chosen as the most similar compounds (ranked with the highest similarity values) to any of the 32 approved antidepressant drugs. Selected compounds represented the "nearest neighbors" of the approved antidepressants. Valproic acid was the most similar antidepressant to GRAS molecules. Based on the knowledge that the inhibition of HDAC1 could be related to the efficacy of valproic acid in the treatment of bipolar disorder, Martinez-Mayorga et al. screened the GRAS compounds most similar to valproic acid for HDAC1 inhibition. The GRAS compounds nonanoic acid and 2decenoic acid inhibited HDAC1 at a micromolar level with a potency comparable to that of valproic acid. Of note is that the GRAS chemicals were not expected to have strong enzymatic inhibitory effects at the concentrations typically employed in flavor formulations designed for use in foods and beverages. However, as shown in that work, GRAS chemicals were able to bind to a relevant therapeutic target. That study also served as a proof-of-principle of the feasibility of exploring the FEMA GRAS flavoring list using computational methods as a potential source of biologically active molecules. In addition, the study demonstrated that similarity searching followed by experimental evaluation could be used for rapid identification of GRAS chemicals with potential bioactivity [19].

In two subsequent and separate studies, Martinez-Mayorga et al. employed structural similarity to compare the FEMA GRAS list with analgesics and with compounds used as satiety agents [105]. The list of analgesics used as query molecules contained ten structurally diverse molecules currently used in clinics. A total of eight satiety agents were identified in the literature, which were used as reference compounds for similarity searching. The satiety agents included those currently used in clinics, as well as those still in clinical trials. In both studies, reference compounds were compared with the FEMA GRAS list using a total of seven structural representations obtained from three different software programs, MOE, ChemAxon, and PowerMV. Compounds identified by different programs and representations were chosen as consensus compounds for additional studies. Then, a chemical space was constructed based on physicochemical properties. Nearest neighbors were identified based on Euclidian distances, considering all the dimensions (properties). Based on the comparison of structural features and physicochemical properties, two FEMA GRAS compounds were selected as being similar to the reference analgesics. In the second study, a total of nine FEMA GRAS molecules were identified as being similar to those used as reference satiety agents. For compounds having a known mode of action, in vitro studies using the identified GRAS chemicals could help determine whether or not they may have a satiety or analgesic effect in humans. However, it must be considered that in the large majority of cases biological effects result from complex and multiple interactions in the body [105].

As previously discussed in this review, phytochemicals derived from edible plants are notable sources of bioactive molecules. In a recent study, Jensen et al. [106] performed a high-throughput analysis of phytochemicals in order to reveal associations between diet and health benefits using text mining and chemoinformatic methods. The first step of that work was the retrieval of associations between the terms plants and phytochemicals from 21 million abstracts in PubMed/MEDLINE during the period 1998-2012. This information was merged with the Chinese Natural Product Database and the Ayurveda data set, which was also curated by the authors. The final data set included nearly 37000 phytochemicals. A major outcome of that study is the structured and standardized database of phytochemicals associated with medicinal plants. The authors pointed out that their approach facilitates the identification of novel bioactive compounds from natural sources, and the repurposing of medicinal plants for diseases other than those for which they are traditionally used, with the added benefit that the information collected can help elucidate a mechanism of action [106]. As a case study, Jensen et al. conducted structural similarity searching in order to find molecules in their compiled database of phytochemicals with activity against a protein involved in the colon cancer pathway or a colon cancer drug target. The reference compounds were those reported in ChEMBL. A set of molecules from this study not only showed reported health benefits against colon cancer, but activity was also verified against colon cancer protein targets [106].

\section{Polypharmacology and Chemogenomics in Natural Products Research $\nabla$}

The increasing awareness that a drug may have its clinical effect through the interaction of multiple targets (called "polypharmacology") is changing the drug discovery paradigm from a single target to a multi-target approach [31]. This change is enriching chemogenomics data sets that capture ligand-target relationships [111]. As a consequence, a number of computational and experimental approaches are being developed to generate, store, analyze, mine, and visualize target-ligand interactions that define chemogenomic spaces [112-114].

Using the literature reports, the identification of the pharmacological evaluation of compounds (in particular with novel chemical structures) isolated from natural sources is frequent. The pharmacological evaluation usually includes a handful of biological endpoints. In light of the generation of chemogenomics data sets, natural products are being evaluated systematically across a large number of biological endpoints, and the screening data is being released to the public. A representative example of a chemogenomics data set that contains natural products is the large microarray data released by Clemons et al. [115]. In that work, the authors evaluated the binding specificity of 2477 natural products (which were part of a larger collection with 15000 compounds) across 100 sequence-unrelated proteins. The authors released the results of the screening to the public domain (the interested reader has access to the screening data along with the chemical structures in the paper of Clemons et al. [115]). The microarray data set has been analyzed with chemoinformatic approaches with the goal of elucidating the SAR; in particular to uncover structural characteristics related to the selectivity or promiscuity of the molecules using fingerprint or substructure rep- 
resentations [116-118]. For instance, Yongye and Medina-Franco developed the SPID metric to quantify and uncover specific structural changes that have a significant impact on the number of proteins to which a compound binds [116]. In a subsequent publication, Dimova et al. reported an analysis of the same data set using matched molecular pairs [119] to identify single-site substitutions that are associated with large magnitude differences in apparent compound promiscuity. The results of Dimova et al. further confirmed the results of Yongye and Medina-Franco previously published in that promiscuity can be induced by small chemical substitutions.

\section{Docking}

$\nabla$

The concept of one disease/one target was a milestone in modern molecular medicine because it enabled the simplification of complex in vivo symptoms and related them to simple in vitro models. Though this paradigm is shifting to multitargets [31] as our knowledge progresses, this reductionist approach did prove successful in many diseases. To better understand the molecular mechanism of action of molecules on their biological targets, several methods were developed to determine the 3D structure of these proteins, e.g., X-ray, NMR, and electron microscopy. During the past decades, the number of solved protein crystallographic structures grew exponentially, and now tops at 94000 structures (statistics from the PDB homepage [120]). At the same time, computer power has also increased dramatically. Molecular modelling software could then be developed to exploit these types of data. The first docking software was DOCK [121]. Docking refers to methods that predict the orientation of a molecule bound to another. The stabilities or the affinities of the resulting complex are estimated by a mathematical or scoring function [122]. Many different strategies and algorithms for docking exist, e.g., AutoDock [123], FlexX [124], Glide [125], Gold [126], and Surflex [127], to predict the positioning of molecules into the proteinbinding site. Authors have also studied scoring methods to improve the hit rate. Many are related to their cognate docking software (refer to the review by Li et al. [128] describing 20 scoring functions). Because different docking software and scoring functions have different strengths and weaknesses, several authors tested the combination of docking and scoring methods to find the optimal procedure [129], while others proposed to use consensus scoring to accommodate the weaknesses [130-133]. The scoring of the predicted poses from docking will be performed by several scoring functions, not only by one. Predictions well scored by multiple scoring functions will be better ranked. Interested readers can refer to [134] for a review of several consensusscoring methods. As the scoring is dependent on the pose predictions, authors have also worked on improving this step by using consensus docking. It consists in retaining the poses predicted by a majority of docking software [135-137]. In an ideal case, the software can be selected because the natural substance is structurally related to either a ligand or a receptor, or even both, which belong to the software's calibration set resulting in a higher confidence that the computed solutions are trustworthy [138]. Sometimes docking problems arise when the target receptor is a constitutively inactive mutant or exists in unliganded states (inactive vs. active); it could also be under allosteric control (conformational modulation) [139].

Natural products remain a large source of active products and also an inspirational source for medicinal chemists; most of the re- sources, particularly from the microorganisms, are underexploited [12]. Structure-based techniques constitute a possible way to find new applications to these natural products. The majority of drugs in oncology and biocide products are derived from natural products. It is not surprising that many docking studies with natural products fall in these therapeutic domains.

Thiyagarajan et al. [140] targeted FAK by docking a library of 109 natural products. Four selected candidates showed activity of C6 glioma and N18 neuroblastoma cell lines by promoting apoptosis. Medina-Franco and Yoo [104] screened by combining structure-based pharmacophore filtering and docking on DNMT with a library composed of natural products, approved drugs, a DNMT-focused library, and general screening compounds. One hundred and eight potential hits were disclosed to the scientific community for experimental validation. Hussain et al. [141] adopted a docking strategy coupled to a 3D-QSAR to predict the activity of the analogues of aplyronine A that bind to actin. Their models may be helpful in designing more efficient and tolerable antitumor agents.

Docking may be used to assess the binding mode of natural products and subsequently guide the design of more potent candidates. For instance, the comparative docking of forskolin (activator) and labd-13(E)-ene-8a,15-diol diterpene (inhibitor) into the active site of adenylyl cyclase revealed important features in the binding mode of the activator and the inhibitor, allowing for the design of potential cytotoxic and cytostatic agents against cancer cells [142].

Due to antibiotic multiresistant bacteria, finding a new class of antibiotics with a new mode of action has become of paramount importance. This can be evidenced by numerous public fundings at national or international levels. A list of the multimillion Euros projects financed by the EU can be found in [143]. It is noteworthy that the NABATIVI project [144] succeeded in finding a peptidomimetic product with a new mode of action targeting a membrane receptor [145]. This product is in clinical trial phase II. Docking techniques were extensively applied not only to discover new antibiotics but also antiviral, antifungal, or antiprotozoan products. One strategy that is successful so far is to target essential bacterial genes, whose inhibition will kill the microorganisms. An example of a structure-based screening on an essential gene such as the filamenting temperature-sensitive mutant $\mathrm{Z}$ (FtsZ) provides promising leads [146]. Other authors also performed docking studies to demonstrate the bactericidal potentiality of xanthone derivatives [147]. An interesting use of docking was exemplified by Harris et al. [148]. They performed docking on the bacterial essential enzyme peptidyl-tRNA hydrolase to identify possible active compounds and guide their activity-directed isolation to discover antibacterial molecules from an ethanol bark extract of Syzygium johnsonii. For examples of drug discovery from natural compounds using docking to target viruses, fungi, and protozoan parasites, the reader is invited to consult the following respective works: [149] reviewed several in silico approaches to tackle urgent threats caused by new viruses or their variants (HIV, SARS, etc.) and how helpful computational techniques were to disclose the antiviral properties of natural products; docking studies helped to hypothesize the mechanism of action of antifungal pyranocoumarin derivatives in [150,151]; the authors performed docking studies with geldanamycin targeting the HSP90 homolog proteins of pathogenic protozoans Plasmodium falciparum, Leishmania donovani, Trypanosoma brucei, and Entamoeba histolytica. This work allowed for designing 
Table 4 Databases useful for target fishing.

\begin{tabular}{|c|c|c|c|c|}
\hline Database name & Accessibility & Data types & Advantages & Drawbacks \\
\hline PDB [155] & $\begin{array}{l}\text { Freely accessible http://www. } \\
\text { rcsb.org/pdb }\end{array}$ & $\begin{array}{l}94000 \text { Protein structures } \\
\text { with unique PDB code }\end{array}$ & $\begin{array}{l}\text { Reference database; standard } \\
\text { PDB format }\end{array}$ & $\begin{array}{l}\text { Lack of data about biological } \\
\text { activities }\end{array}$ \\
\hline BRENDA [156] & $\begin{array}{l}\text { Freely accessible http://www. } \\
\text { brenda-enzymes.org }\end{array}$ & $\begin{array}{l}4800 \text { Enzymes; ligands; orga- } \\
\text { nisms; biological activities }\end{array}$ & $\begin{array}{l}\text { Very comprehensive data- } \\
\text { base }\end{array}$ & Only enzymes \\
\hline TTD [157] & $\begin{array}{l}\text { Freely accessible http://bidd. } \\
\text { nus.edu.sg/group/cjttd/ } \\
\text { TTD_HOME.asp }\end{array}$ & $\begin{array}{l}1900 \text { Targets; } 5000 \text { ligands; } \\
\text { biological pathways and ac- } \\
\text { tivities; patents }\end{array}$ & $\begin{array}{l}\text { Very useful for reverse phar- } \\
\text { macognosy; frequently up- } \\
\text { dated }\end{array}$ & $\begin{array}{l}\text { Relatively small amount of } \\
\text { data }\end{array}$ \\
\hline PDTD [158] & $\begin{array}{l}\text { Freely accessible http://www. } \\
\text { dddc.ac.cn/pdtd/index.php }\end{array}$ & $\begin{array}{l}1200 \text { Aelected protein struc- } \\
\text { tures; biological activities; } \\
\text { cross-linked with other data- } \\
\text { bases }\end{array}$ & $\begin{array}{l}\text { Link to TarFisDock, an inverse } \\
\text { screening platform }\end{array}$ & $\begin{array}{l}\text { Relatively small amount of } \\
\text { data }\end{array}$ \\
\hline Sc-PDB [159] & $\begin{array}{l}\text { Freely accessible http:// } \\
\text { bioinfo-pharma.u-strasbg.fr/ } \\
\text { scPDB }\end{array}$ & $\begin{array}{l}\text { 3D structures selected from } \\
\text { PDB }\end{array}$ & $\begin{array}{l}\text { Useful to enrich a target data- } \\
\text { base for inverse screening }\end{array}$ & Only a subset of PDB \\
\hline Drug Bank [160] & $\begin{array}{l}\text { Freely accessible http://www. } \\
\text { drugbank.ca }\end{array}$ & $\begin{array}{l}2500 \text { Proteins; } 4800 \text { drugs; } \\
\text { pathways }\end{array}$ & $\begin{array}{l}\text { Important part of FDA-ap- } \\
\text { proved drugs and proteins }\end{array}$ & $\begin{array}{l}\text { Lack of data about biological } \\
\text { activities }\end{array}$ \\
\hline ChEM BL [160] & $\begin{array}{l}\text { Freely accessible https:// } \\
\text { www.ebi.ac.uk/chembldb/ }\end{array}$ & $\begin{array}{l}1.4 \text { Million compounds; } \\
10000 \text { targets; } 13 \text { millions } \\
\text { activities }\end{array}$ & Very comprehensive & $\begin{array}{l}\text { Results may be complex to } \\
\text { analyze }\end{array}$ \\
\hline
\end{tabular}

selective analogues of protozoan HSP90 with a reduced affinity to the human homologue.

Finally, some investigators applied docking on several targets to identify molecules with synergistic effects on a particular biological pathway, e.g., modulation of testosterone [10]. Bernard et al. identified honokiol as a dose-dependent inhibitor of aromatase and 5-alpha-reductase 1; the inhibition of both enzymes mitigates the decrease of the testosterone level in aging men. Noteworthy is that honokiol is not active on the 5-alpha-reductase 2.

\section{Target Fishing}

The researchers quoted above not only applied docking to screening but also for identifying putative interacting protein partners (or "target fishing"), hence the mode of action of natural compounds. In each case, the authors have to hypothesize the possible target based on an "educated guess" or hints from the scientific literature. A docking study is performed with the active molecules to the selected protein target, and the score of the complex is evaluated. According to this score, the authors will then judge the plausibility of that ligand-protein interaction. An obvious caveat of such an approach resides in the picking of the targets, which will miss targets that are not evident or targets not yet known to be related to the biological effects.

To circumvent this difficulty and explore systematically possible interactions of a molecule with proteins, inverse docking was first introduced by Chen and Zhi in 2007 [152]. It consists in docking a molecule to a set of 3D protein structures. Therefore, inverse docking is in need of a docking program (see previous section) or a more specific tool in combination with a database of 3D protein structures (see - Table 4 for a list of possible databases). Docking software generally lacks the ability to correctly rank possible ligands in one site. This represents a serious limitation. Several authors developed corrected scoring functions to work around this limitation [153] and demonstrated the feasibility of this technique [154]. Vigers and Rizzi [153] showed that their new scoring function could assess the selectivity of compounds among a family of proteins, such as kinases, and selectivity among proteins of unrelated families.
Inverse docking plays a key role in the concept of "reverse pharmacognosy" introduced by Do and Bernard [161] and extended by Blondeau et al. [17]. Pharmacognosy starts with natural sources (e.g., extracts of plants and microorganisms) and thanks to activity-guided fractionation, identifies the molecule(s) responsible for a biological activity. Conversely, reverse pharmacognosy begins with a natural molecule and, thanks to inverse docking, identifies putative targets of interest. The predictions are then validated with related in vitro assays. Thanks to a database linking molecules and the organisms producing them, we can identify new applications for plants, for example, with the mode of action at the molecular level (ligand-protein interactions). With this approach, Do et al. could identify protein interacting partners for epsilon-viniferin from Vitis vinifera, which inhibits phosphodiesterase 3 and 4 [162], and for meranzin from Limnocitrus littoralis, which blocks COX 1 and 2, and activates PPAR- $\gamma$ [163]. Thus, extracts from these two plants at an adequate concentration of the active molecules may be used in indications involving the described proteins.

Other scenarios of inverse docking were described for pharmacological profiling of natural products [164], either to understand the mode of action as well as repurpose molecules, e.g., tanshinone II a [165], or to evaluate the toxicity profile [166].

Only a few software programs have been developed for inverse docking, but the field is gaining more and more attention, as we can notice through the development of tools based on an existing docking engine or on a specific software: Invdock [152], iRAISE [167], Mdock [168], Selnergy [161] based on the Surflex programme, Tarfisdock [169] based on the DOCK programme, and TarSearch-X [170]. Inverse docking is not yet mature technology but should mutually fertilize other approaches, e.g., chemogenomics and bioinformatics.

It should be mentioned that inverse docking is one out of the several techniques available to conduct target fishing. Other common approaches such as data mining and similarity searching (see above) are extensively used to explore putative targets of bioactive compounds. In similarity searching, targets are represented by their ligands and query molecules are compared with the known ligands. Based on the concept of SAR, similar molecular structures will certainly have similar biological activities. 
Thus, by finding similar ligands to query structures, one can relate the query compounds to the ligands' targets. Databases such as DrugBank, PubChem, and ChEMBL [171] are key to have as many as possible interaction pairs of ligands and targets. Machine learning techniques (e.g., Support Vector Machine, Neural Networks $[172,173]$ ) are also popular to identify the relationship of molecules and possible targets. These systems are usually trained with a training set of known pairs of ligands/proteins based on descriptors, then validated with an external validation set (known pairs of ligands/proteins not used to build the models). We will evoke in the next paragraph the different types of descriptors. Structure-based and other computational approaches for target fishing are reviewed elsewhere $[80,174]$.

\section{Pharmacophoric and Other Descriptors in Virtual Screening \\ $\nabla$}

A crucial point for the success of virtual screening is the design of the filter layer that constitutes the similarity patterns to retrain the potential candidates and discard the reminder. Many virtual screening programs have special graphical or scripting methods to write such filter definitions. Sometimes they consist of physicochemical properties, for example, "filter out all compounds with $\mathrm{pK}_{\mathrm{a}}$ greater than ... and/or without aryl rings ... and/or with a nonpolar surface larger than". On occasion, they also describe a substructure of the scaffold common to all or almost all expected hit compounds. The underlying assumption is twofold: (1) the existence of a pharmacophore, "an ensemble of steric and electronic features that is necessary to ensure the optimal supramolecular interactions with a specific biological target and to trigger (or block) its biological response" $[78,175]$ and (2) similar chemicals have similar biological activities [176]. Ligand-based virtual screening for structures with similar pharmacophoric patterns has become a successful method to identify potential drug candidates. Some of the latter find their role as lead compounds for lead expansion, lead hopping, and scaffold hopping in the desired therapeutic area. When 3D structures or homology models of the target protein are available, protein-based screening can be carried out. The pharmacophore defines spatial requirements like interatomic distances, angles, or the location of particular properties, and ionic sites as well as other descriptors that depend on the spatial coordinates. Such 3D information renders the screening query (filter) more precise but also more error-prone. Hence, not unexpectedly, researchers noticed that virtual screening based on 2D fingerprints (filter concepts based on atoms and bonds and their connectivity but without spatial coordinates) could be more successful than 3D pharmacophore. The authors recommended the combination of 2D and 3D descriptors [176]. Sometimes the sheer number of conformations under which compounds are collected is so overwhelming that the docking, screening, or simply identifying relationships between compounds based on their shape similarities risks overthrowing the computer resources at hand. Thus, screening for whole molecules, their side chain substituents, or their central scaffolds by conformationally-independent topomer similarities becomes a useful strategy. The partitioning of solutes in liquids along with surface defining descriptors, like nonpolar surface area, solvent accessibility, etc., is commonly applied in ADMET prediction models or in studies of membrane crossing, transport into cell compartments, or diffusion kinetics. The partial charges of the compounds can be calculated and projected as isocontour lines in the space surrounding the molecule of interest. TARIS is an approach based on such molecular EPS. The classes and types of descriptors are far too many, thereby lying beyond the scope of this review [177] (refer to topics in cheminformatics, e.g., GETAWAY, 3D MoRSE, MS-WHIM, FEPOPS circular fingerprints, MACCS keys, or graph-based multi-point pharmacophore as well as the socalled ROCS shape descriptors $[178,179])$. ROC profiles (receiver operating characteristics) show a sort of hit enrichment in the final solution list against other compounds, e.g., decoys for testing (benchmarking), docking, and screening simulations. They have highly similar structures but are biologically inactive. A well-performing method should discard them from the hit list [180]. Although the number of descriptors used in a study may end up in the thousands, the right choice remains a challenging task of its own kind. Apparently, descriptors fail in reflecting in exactly which item the molecules resemble each other. PCA, a sort of statistical factorial analysis, simplifies the level of data complexity to a minimum set of orthogonal (independent) diagram axes (factors or components). PCA eventually sheds some light and explains some of the failures and downside when molecules are screened [181].

When needing to save time and running costs, HTS can be elegantly simulated in silico by screening virtual libraries (vHTS) [182]. To this end, vHTS descriptors have been developed, which do not need a lengthy superposition of data set molecules (for comparison) like PESD or UFSR. In addition, other techniques have been developed, for instance, $2 \mathrm{D}$ and higher dimensional QSAR, SVM, rule-based methods, or ANN [28]. ANN outperforms rule-based pharmacophore screens in those cases when decision taking in a straightforward manner is not behaving well, or tenets are ill-designed or believed to be just "better than no rule at all". Such rule-based pharmacophore screens generally make use of binary variables (simple "Yes/No" criteria) or integer values (the Lipinski's rule-of-five, more than five hydrogen bonds, etc.). The architecture of ANNs is based on a multilayer of criteria with individual weight put on them by training, i.e., probabilities of their contribution to yield the right answer which is a priori known during ANN training. What the ANN learned (as a black box to the user) through the training set of known cases is then applied to the test set. Although very complex phenomena can be handled, wrong answers emerge, mostly in cases when the molecule has unforeseeable characteristics.

\section{Conclusions and Perspectives \\ $\nabla$}

Thanks to the large amount of information accumulated on natural product research, in silico techniques related to chemoinformatics, database mining, and molecular modeling facilitate the use of this information to further valorize natural products as a source and/or inspiration of drugs. In silico approaches enable the characterization of their physicochemical profile, analysis of chemical diversity, coverage of chemical space, and uncovering of trends in their SAR. The outcome of such analyses is valuable to guide medicinal chemistry efforts to optimize their properties or inspire the synthesis of novel scaffolds. Molecular modeling approaches, either ligand based or structure based, coupled with experimental methods, constitute techniques of choice to identify putative biological properties for natural products in a systematic manner and thus find ways to valorize them. To this end, numerous authors have applied computational structure similarity techniques to the GRAS list compounds [19] to repurpose them 
as potential functional foods or use reverse pharmacognosy to find new uses for the molecules and their sources [18]. Although in this review we only examine health-related aspects of natural product utility, many applications can be found in numerous domains, such as material science and energy engineering among others. With new insights in microorganism biomes, the possibilities offered by Nature become even more tremendous [12], and preserving biodiversity has never been so crucial even at the restrictive economical point of view. It is anticipated that in silico approaches will continue to be part of the research to study and further potentiate the use of biodiversity.

\section{Acknowledgements}

$\nabla$

We thank Dr. Karina Martinez-Mayorga for her insightful discussions, stimulating ideas, and fruitful conversations.

\section{Conflict of Interest}

$\nabla$

The authors declare that they do not have any conflict of interest.

\section{References}

1 Convention on biological diversity. Montreal: Secretariat of the Convention on Biological Diversity; 2012

2 Pimm SL, Jenkins CN, Abell R, Brooks TM, Gittleman JL, Joppa LN, Raven $P H$, Roberts CM, Sexton JO. The biodiversity of species and their rates of extinction, distribution, and protection. Science 2014; 344: 1246752

3 Rao M, Htun S, Platt SG, Tizard R, Poole C, Myint T, Watson JE. Biodiversity conservation in a changing climate: a review of threats and implications for conservation planning in Myanmar. Ambio 2013; 42: 789804

4 Camp D, Newman S, Pham NB, Quinn RJ. Nature Bank and the Queensland Compound Library: unique international resources at the Eskitis Institute for Drug Discovery. Comb Chem High Throughput Screen 2014: 17: 201-209

5 http://www.ffem.fr/lang/en/accueil/activites-ffem/biodiversite protection. Accessed September 26, 2013

6 http://www.marex.fi/. Accessed September 26, 2013

7 Burton RA, Fincher GB. Plant cell wall engineering: applications in biofuel production and improved human health. Curr Opin Biotechnol 2014; 26: 79-84

8 Huskinson B, Marshak MP, Suh C, Er S, Gerhardt MR, Galvin CJ, Chen X, Aspuru-Guzik A, Gordon RG, Aziz MJ. A metal-free organic-inorganic aqueous flow battery. Nature 2014; 505: 195-198

9 Bhushan B. Biomimetics: lessons from nature-an overview. Philos Trans A Math Phys Eng Sci 2009; 367: 1445-1486

10 Bernard P, Scior T, Do QT. Modulating testosterone pathway: a new strategy to tackle male skin aging? Clin Interv Aging 2012; 7: 351-361

11 Graziose R, Lila MA, Raskin I. Merging traditional Chinese medicine with modern drug discovery technologies to find novel drugs and functional foods. Curr Drug Discov Technol 2010; 7: 2-12

12 Newman DJ, Cragg GM. Natural products as sources of new drugs over the 30 years from 1981 to 2010. J Nat Prod 2012; 75: 311-335

13 Berkov S, Mutafova B, Christen P. Molecular biodiversity and recent analytical developments: a marriage of convenience. Biotechnol Adv 2014; 32: 1102-1110

14 Merelli I, Pérez-Sánchez H, Gesing S, D’Agostino D. Managing, analysing, and integrating big data in medical bioinformatics: open problems and future perspectives. Biomed Res Int 2014; 2014: e134023

15 Eid S, Zalewski A, Smieško M, Ernst B, Vedani A. A Molecular-Modeling Toolbox Aimed at Bridging the Gap between Medicinal Chemistry and Computational Sciences. Int J Mol Sci 2013; 14: 684-700

16 Medina-Franco JL, Martínez-Mayorga K, Peppard TL, Del Rio A. Chemoinformatic analysis of GRAS (Generally Recognized as Safe) flavor chemicals and natural products. PLoS One 2012; 7: e50798

17 Blondeau S, Do QT, Scior T, Bernard P, Morin-Allory L. Reverse pharmacognosy: another way to harness the generosity of nature. Curr Pharm Des 2010; 16: 1682-1696
18 Do QT, Driscoll M, Slitt A, Seeram N, Peppard TL, Bernard P. Reverse pharmacognosy: a tool to accelerate the discovery of new bioactive food ingredients. In: Martinez-Mayorga K, Medina-Franco JL, editors. Food informatics: applications of chemical information to food chemistry. Heidelberg: Springer; 2014: 111-130

19 Martinez-Mayorga K, Peppard TL, López-Vallejo F, Yongye AB, MedinaFranco JL. Systematic mining of Generally Recognized as Safe (GRAS) flavor chemicals for bioactive compounds. J Agric Food Chem 2013; 61: 7507-7514

20 Audouze K, Tromelin A, Le Bon AM, Belloir C, Petersen RK, Kristiansen K, Brunak S, Taboureau O. Identification of odorant-receptor interactions by global mapping of the human odorome. PLoS One 2014; 9: e93037

21 Bernard P, Scior T, Didier B, Hibert M, Berthon JY. Ethnopharmacology and bioinformatic combination for leads discovery: application to phospholipase A(2) inhibitors. Phytochemistry 2001; 58: 865-874

22 Rollinger JM, Haupt S, Stuppner H, Langer T. Combining ethnopharmacology and virtual screening for lead structure discovery: COX-inhibitors as application example. J Chem Inf Comput Sci 2004; 44: 480-488

23 Kerns EH. High throughput physicochemical profiling for drug discovery. J Pharm Sci 2001; 90: 1838-1858

24 Avdeef A, Testa B. Physicochemical profiling in drug research: a brief survey of the state-of-the-art of experimental techniques. Cell Mol Life Sci 2002; 59: 1681-1689

25 Sinko JS. Drug selection in early drug development: screening for acceptable pharmacokinetic properties using combined in vitro and computational approaches. Curr Opin Drug Discov Devel 1999; 2: 4248

26 Cartmell J, Krstajic D, Leahy DE. Competitive Workflow: novel software architecture for automating drug design. Curr Opin Drug Discov Devel 2007; 10: 347-352

27 Scior T, Bernard P, Medina-Franco JL, Maggiora GM. Large compound databases for structure-activity relationships studies in drug discovery. Mini Rev Med Chem 2007; 7: 851-860

28 Scior T, Medina-Franco JL, Do QT, Martínez-Mayorga K, Yunes Rojas JA, Bernard $P$. How to recognize and workaround pitfalls in QSAR studies: a critical review. Curr Med Chem 2009; 16: 4297-4313

29 Kirchmair J, Williamson MJ, Tyzack JD, Tan L, Bond PJ, Bender A, Glen RC. Computational prediction of metabolism: sites, products, SAR, P450 enzyme dynamics, and mechanisms. J Chem Inf Model 2012; 52: 617 648

30 Fang $Y$. Label-free drug discovery. Front Pharmacol 2014; 5: 1-8

31 Medina-Franco JL, Giulianotti MA, Welmaker GS, Houghten RA. Shifting from the single to the multitarget paradigm in drug discovery. Drug Discov Today 2013; 18: 495-501

32 Lobell M, Hendrix M, Hinzen B, Keldenich J, Meier H, Schmeck C, SchoheLoop R, Wunberg T, Hillisch A. In silico ADMET traffic lights as a tool for the prioritization of HTS hits. ChemMedChem 2006; 1: 1229-1236

33 Lipinski CA, Lombardo F, Dominy BW, Feeney PJ. Experimental and computational approaches to estimate solubility and permeability in drug discovery and development settings. Adv Drug Deliv Rev 2001; 46: $3-$ 26

34 Veber DF, Johnson SR, Cheng HY, Smith BR, Ward KW, Kopple KD. Molecular properties that influence the oral bioavailability of drug candidates. J Med Chem 2002; 45: 2615-2623

35 Blake JF. Examination of the computed molecular properties of compounds selected for clinical development. Biotechniques 2003; 34: S16-S20

36 Wenlock MC, Austin RP, Barton P, Davis AM, Leeson PD. A comparison of physiochemical property profiles of development and marketed oral drugs. J Med Chem 2003; 46: 1250-1256

37 Palm K, Stenberg P, Luthman K, Artursson P. Polar molecular surface properties predict the intestinal absorption of drugs in humans. Pharm Res 1997; 14: 568-571

38 Clark DE. Rapid calculation of polar molecular surface area and its application to the prediction of transport phenomena. 1. Prediction of intestinal absorption. J Pharm Sci 1999; 88: 807-814

39 Ritchie TJ, Macdonald SJ. The impact of aromatic ring count on compound developability-are too many aromatic rings a liability in drug design? Drug Discov Today 2009; 14: 1011-1020

40 Di L, Kerns EH. Profiling drug-like properties in discovery research. Curr Opin Chem Biol 2003; 7: 402-408

41 Cruz-Monteagudo M, Cordeiro MN. Chemoinformatics profiling of ionic liquids-uncovering structure-cytotoxicity relationships with networklike similarity graphs. Toxicol Sci 2014; 138: 191-204 
42 Pedretti A, Villa L, Vistoli G. VEGA: a versatile program to convert, handle and visualize molecular structure on Windows-based PCs. J Mol Graph Model 2002; 21: 47-49

43 Carrió P, Pinto M, Ecker G, Sanz F, Pastor M. Applicability Domain ANalysis (ADAN): a robust method for assessing the reliability of drug property predictions. J Chem Inf Model 2014; 54: 1500-1511

44 Norinder U, Carlsson L, Boyer S, Eklund M. Introducing conformal prediction in predictive modeling. A transparent and flexible alternative to applicability domain determination. J Chem Inf Model 2014; 54: 1596-1603

45 Moura-Barbosa AJ, Del Rio A. Freely accessible databases of commercial compounds for high-throughput virtual screenings. Curr Top Med Chem 2012; 12: 866-877

46 Blunt JW, Munro MHG, Laatsch H. AntiMarin database. Christchurch: University of Canterbury. Göttingen: University of Göttingen; 2007

47 Pereira F, Latino DA, Gaudêncio SP. A chemoinformatics approach to the discovery of lead-like molecules from marine and microbial sources en route to antitumor and antibiotic drugs. Mar Drugs 2014; 12: 757-778

48 Newman DJ, Cragg GM. Natural products as sources of new drugs over the last 25 years. J Nat Prod 2007; 70: 461-477

49 Newman DJ, Cragg GM, Snader KM. Natural products as sources of new drugs over the period 1981-2002. J Nat Prod 2003; 66: 1022-1037

50 DiMasi JA. Pharmaceutical R\&D performance by firm size: approval success rates and economic returns. Am J Ther 2014; 21: 26-34

51 Bergström CA, Holm R, Jørgensen SA, Andersson SBA, Artursson P, Beato S, Borde A, Box K, Brewster M, Dressman J, Feng KI, Halbert G, Kostewicz E, McAllister M, Muenster U, Thinnes J, Taylor R, Mullertz A. Early pharmaceutical profiling to predict oral drug absorption: current status and unmet needs. Eur J Pharm Sci 2014; 57: 173-199

52 Keller TH, Pichota A, Yin Z. A practical view of 'druggability'. Curr Opin Chem Biol 2006; 10: 357-361

53 Kellenberger E, Hofmann A, Quinn RJ. Similar interactions of natural products with biosynthetic enzymes and therapeutic targets could explain why nature produces such a large proportion of existing drugs. Nat Prod Rep 2011; 28: 1483-1492

54 Feher M, Schmidt JM. Property distributions: differences between drugs, natural products, and molecules from combinatorial chemistry. J Chem Inf Comput Sci 2003; 43: 218-227

55 Ortholand JY, Ganesan A. Natural products and combinatorial chemistry: back to the future. Curr Opin Chem Biol 2004; 8: 271-280

56 Messer R, Fuhrer CA, Häner R. Natural product-like libraries based on non-aromatic, polycyclic motifs. Curr Opin Chem Biol 2005; 9: 259265

57 Camp D, Davis RA, Campitelli M, Ebdon J, Quinn RJ. Drug-like properties: guiding principles for the design of natural product libraries. J Nat Prod 2012; 75: 72-81

58 Rishton GM. Reactive compounds and in vitro false positives in HTS. Drug Discov Today 1997; 2: 382-384

59 Hughes JP, Rees S, Kalindjian SB, Philpott KL. Principles of early drug discovery. Br J Pharmacol 2011; 162: 1239-1249

60 Ntie-Kang F, Zofou D, Babiaka SB, Meudom R, Scharfe M, Lifongo LL, Mbah JA, Mbaze LM, Sippl W, Efange SM. AfroDb: a select highly potent and diverse natural product library from African medicinal plants. PLoS One 2013; 8: e78085

61 Ntie-Kang F, Amoa Onguéné P, Fotso GW, Andrae-Marobela K, Bezabih M, Ndom JC, Ngadjui BT, Ogundaini AO, Abegaz BM, Meva'a LM. Virtualizing the p-ANAPL library: a step towards drug discovery from African medicinal plants. PLoS One 2014; 9: e90655

62 Buckingham J. Dictionary of natural products. London: Chapman \& Hall; 1994

63 Duke J. Dr. Duke's phytochemical and ethnobotanical databases. ARS, USDA. Available at http://www.ars-grin.gov/duke (Oct 2009). Accessed September 26, 2013

64 Nakamura Y, Afendi FM, Parvin AK, Ono N, Tanaka K, Hirai Morita A, Sato T, Sugiura T, Altaf-Ul-Amin M, Kanaya S. KNApSAcK Metabolite Activity Database for retrieving the relationships between metabolites and biological activities. Plant Cell Physiol 2014; 55: e7

65 Loub WD, Farnsworth NR, Soejarto DD, Quinn ML. NAPRALERT: computer handling of natural product research data. J Chem Inf Comput Sci 1985; 25: 99-103

66 Plant for a future database. Available at http://www.pfaf.org Oct 2009. Accessed September 26, 2013

67 Dunkel M, Fullbeck M, Neumann S, Preissner R. SuperNatural: a searchable database of available natural compounds. Nucleic Acids Res 2006; 34: 678-683
68 Chen X, Zhou H, Liu YB, Wang JF, Li H, Ung CY, Han LY, Cao ZW, Chen YZ. Database of traditional Chinese medicine and its application to studies of mechanism and to prescription validation. Br J Pharmacol 2006; 149: 1092-1103

$69 \mathrm{Gu} J$, Gui Y, Chen L, Yuan G, Lu HZ, Xu X. Use of natural products as chemical library for drug discovery and network pharmacology. PLoS One 2013; 8: e62839

70 Bender A, Glen RC. Molecular similarity: a key technique in molecular informatics. Org Biomol Chem 2004; 2: 3204-3218

71 Stumpfe D, Hu Y, Dimova D, Bajorath J. Recent progress in understanding activity cliffs and their utility in medicinal chemistry. J Med Chem 2014; 57: 18-28

72 Medina-Franco JL. Scanning structure-activity relationships with structure-activity similarity and related maps: from consensus activity cliffs to selectivity switches. J Chem Inf Model 2012; 52: 2485-2493

73 Yue R, Shan L, Yang X, Zhang W. Approaches to target profiling of natural products. Curr Med Chem 2012; 19: 3841-3855

74 Méndez-Lucio O, Tran J, Medina-Franco JL, Meurice N, Muller M. Towards drug repurposing in epigenetics: olsalazine as a novel hypomethylating compound active in a cellular context. ChemMedChem 2014; 9 : 560-565

75 Villoutreix BO, Eudes $R$, Miteva MA. Structure-based virtual ligand screening: recent success stories. Comb Chem High Throughput Screen 2009; 12: 1000-1016

76 Ripphausen P, Nisius B, Bajorath J. State-of-the-art in ligand-based virtual screening. Drug Discov Today 2011; 16: 372-376

77 López-Vallejo F, Caulfield T, Martínez-Mayorga K, Giulianotti MA, Nefzi A, Houghten RA, Medina-Franco JL. Integrating virtual screening and combinatorial chemistry for accelerated drug discovery. Comb Chem High Throughput Screen 2011; 14: 475-487

78 Scior T, Bender A, Tresadern G, Medina-Franco JL, Martínez-Mayorga K Langer T, Cuanalo-Contreras K, Agrafiotis DK. Recognizing pitfalls in virtual screening: a critical review. J Chem Inf Model 2012; 52: 867-881

79 Harvey AL, Clark RL, Mackay SP, Johnston BF. Current strategies for drug discovery through natural products. Expert Opin Drug Discov 2010; 5 : 559-568

80 Medina-Franco JL. Advances in computational approaches for drug discovery based on natural products. Rev Latinoam Quim 2013; 41: 95 110

81 Schuster D, Wolber G. Identification of bioactive natural products by pharmacophore-based virtual screening. Curr Pharm Des 2010; 16: 1666-1681

82 Ehrman TM, Barlow DJ, Hylands PJ. Phytochemical informatics and virtual screening of herbs used in Chinese medicine. Curr Pharm Des 2010; 16: 1785-1798

83 Shen JH, Xu XY, Cheng F, Liu H, Luo XM, Shen JK, Chen KX, Zhao WM, Shen $X$, Jiang $H L$. Virtual screening on natural products for discovering active compounds and target information. Curr Med Chem 2003; 10: 2327 2342

$84 \mathrm{Ma}$ DL, Chan DSH, Leung CH. Molecular docking for virtual screening of natural product databases. Chem Sci 2011; 2: 1656-1665

85 Geldenhuys WJ, Bishayee A, Darvesh AS, Carroll RT. Natural products of dietary origin as lead compounds in virtual screening and drug design. Curr Pharm Biotechnol 2012; 13: 117-124

86 Lemmen C, Lengauer T. Computational methods for the structural alignment of molecules. J Comput Aided Mol Des 2000; 14: 215-232

87 Yongye AB, Bender A, Martinez-Mayorga K. Dynamic clustering threshold reduces conformer ensemble size while maintaining a biologically relevant ensemble. J Comput Aided Mol Des 2010; 24: 675-686

88 Medina-Franco JL, Maggiora GM. Molecular similarity analysis. In: Bajorath J, editor. Chemoinformatics for drug discovery. New York: John Wiley \& Sons, Inc.; 2014: 343-399

89 Ebalunode JO, Zheng WF. Unconventional 2D shape similarity method affords comparable enrichment as a 3D shape method in virtual screening experiments. J Chem Inf Model 2009; 49: 1313-1320

90 Hu GP, Kuang GL, Xiao W, Li WH, Liu GX, Tang Y. Performance evaluation of $2 \mathrm{D}$ fingerprint and 3D shape similarity methods in virtual screening. J Chem Inf Model 2012 : 52: 1103-1113

91 Kalászi A, Szisz D, Imre G, Polgár T. Screen3D: a novel fully flexible highthroughput shape-similarity search method. J Chem Inf Model 2014; 54: 1036-1049

92 Zhang $Q$ Muegge I. Scaffold hopping through virtual screening using 2D and 3D similarity descriptors: ranking, voting, and consensus scoring. J Med Chem 2006; 49: 1536-1548 
93 Mendez-Lucio 0, Perez-Villanueva J, Castillo R, Medina-Franco JL. Identifying activity cliff generators of PPAR ligands using SAS maps. Mol Inf 2012; 31: 837-846

94 Cruz-Monteagudo M, Medina-Franco JL, Pérez-Castillo Y, Nicolotti O, Cordeiro MNDS, Borges F. Activity cliffs in drug discovery: Dr. Jekyll or Mr. Hyde? Drug Discov Today 2014; 19: 1069-1080

95 Yongye $A B$, Waddell J, Medina-Franco JL. Molecular scaffold analysis of natural products databases in the public domain. Chem Biol Drug Des 2012; 80: 717-724

96 Medina-Franco JL, Martinez-Mayorga K, Meurice N. Balancing novelty with confined chemical space in modern drug discovery. Expert Opin Drug Discov 2014; 9: 151-165

97 López-Vallejo F, Giulianotti MA, Houghten RA, Medina-Franco JL. Expanding the medicinally relevant chemical space with compound libraries. Drug Discov Today 2012; 17: 718-726

98 Bender A. How similar are those molecules after all? Use two descriptors and you will have three different answers. Expert Opin Drug Discov 2010; 5: 1141-1151

99 Todeschini R, Consonni V. Molecular descriptors for chemoinformatics, 2nd edition. New York: Wiley-VCH; 2009

100 Willett P. Combination of similarity rankings using data fusion. J Chem Inf Model 2013; 53: 1-10

101 Holliday JD, Kanoulas E, Malim N, Willett P. Multiple search methods for similarity-based virtual screening: analysis of search overlap and precision. J Cheminform 2011; 3: 29

102 Yongye A, Byler K, Santos R, Martínez-Mayorga K, Maggiora GM, Medina-Franco JL. Consensus models of activity landscapes with multiple chemical, conformer and property representations. J Chem Inf Model 2011; 51: 1259-1270

103 Guasch L, Sala E, Castell-Auvi A, Cedo L, Liedl KR, Wolber G, Muehlbacher $M$, Mulero M, Pinent M, Ardevol A, Valls C, Pujadas G, Garcia-Vallve S. Identification of PPARgamma partial agonists of natural origin (I): development of a virtual screening procedure and in vitro validation. PLoS One 2012; 7: e50816

104 Medina-Franco JL, Yoo J. Docking of a novel DNA methyltransferase inhibitor identified from high-throughput screening: insights to unveil inhibitors in chemical databases. Mol Div 2013; 17: 337-344

105 Martinez-Mayorga K, Peppard TL, Ramirez-Hernandez AI, Terrazas-Alvarez DE, Medina-Franco JL. Chemoinformatics analysis and structural similarity studies of food-related databases. In: Martinez-Mayorga K, Medina-Franco JL, editors. FoodInformatics: applications of chemical information to food chemistry. Heidelberg: Springer; 2014: 97-110

106 Jensen K, Panagiotou G, Kouskoumvekaki I. Integrated text mining and chemoinformatics analysis associates diet to health benefit at molecular level. PLoS Comput Biol 2014; 10: e1003432

107 Pochetti G, Godio C, Mitro N, Caruso D, Galmozzi A, Scurati S, Loiodice F, Fracchiolla G, Tortorella P, Laghezza A, Lavecchia A, Novellino E, Mazza $F$, Crestani $M$. Insights into the mechanism of partial agonism: crystal structures of the peroxisome proliferator-activated receptor gamma ligand-binding domain in the complex with two enantiomeric ligands. J Biol Chem 2007; 282: 17314-17324

108 Al-Najjar BO, Wahab HA, Tengku Muhammad TS, Shu-Chien AC, Ahmad Noruddin NA, Taha MO. Discovery of new nanomolar peroxisome proliferator-activated receptor $\gamma$ activators via elaborate ligand-based modeling. Eur J Med Chem 2011; 46: 2513-2529

109 Feng Y, Campitelli M, Davis RA, Quinn RJ. Chemoinformatic analysis as a tool for prioritization of trypanocidal marine derived lead compounds. Mar Drugs 2014; 12: 1169-1184

110 Rosén J, Lövgren A, Kogej T, Muresan S, Gottfries J, Backlund A. ChemGPS-NP(Web): chemical space navigation online. J Comput Aided Mol Des 2009; 23: 253-259

111 Rognan $D$. Towards the next generation of computational chemogenomics tools. Mol Inf 2013; 32: 1029-1034

112 Medina-Franco JL, Aguayo-Ortiz R. Progress in the visualization and mining of chemical and target spaces. Mol Inf 2013; 32: 942-953

113 Bajorath J. A perspective on computational chemogenomics. Mol Inf 2013; 32: 1025-1028

114 Kjærulff SK, Wich L, Kringelum J, Jacobsen UP, Kouskoumvekaki I, Audouze K, Lund O, Brunak S, Oprea TI, Taboureau O. ChemProt-2.0: visual navigation in a disease chemical biology database. Nucleic Acids Res 2013; 4: D464-D469

115 Clemons PA, Bodycombe NE, Carrinski HA, Wilson JA, Shamji AF, Wagner $B K$, Koehler AN, Schreiber SL. Small molecules of different origins have distinct distributions of structural complexity that correlate with pro- tein-binding profiles. Proc Natl Acad Sci U S A 2010; 107: 1878718792

116 Yongye $A B$, Medina-Franco JL. Data mining of protein-binding profiling data identifies structural modifications that distinguish selective and promiscuous compounds. J Chem Inf Model 2012; 52: 2454-2461

117 Dimova D, Hu Y, Bajorath J. Matched molecular pair analysis of small molecule microarray data identifies promiscuity cliffs and reveals molecular origins of extreme compound promiscuity. J Med Chem 2012; 55: 10220-10228

118 Yongye $A B$, Medina-Franco JL. Toward an efficient approach to identify molecular scaffolds possessing selective or promiscuous compounds. Chem Biol Drug Des 2013; 82: 367-375

119 Dossetter AG, Griffen EJ, Leach AG. Matched molecular pair analysis in drug discovery. Drug Discov Today 2013; 18: 724-731

120 http://pdb.rcsb.org/pdb/static.do?p=general_information/pdb_ statistics/index.html. Accessed June 22, 2014

121 Kuntz ID, Blaney JM, Oatley SJ, Langridge R, Ferrin TE. A geometric approach to macromolecule-ligand interactions. J Mol Biol 1982; 161: 269-288

122 Lengauer T, Rarey M. Computational methods for biomolecular docking. Curr Opin Struct Biol 1996; 6: 402-406

123 Goodsell DS, Morris GM, Olson AJ. Automated docking of flexible ligands: applications of AutoDock. J Mol Recognit 1996; 9: 1-5

124 Rarey M, Kramer B, Lengauer T, Klebe G. A fast flexible docking method using an incremental construction algorithm. J Mol Biol 1996; 261: 470-489

125 Friesner RA, Banks JL, Murphy RB, Halgren TA, Klicic JJ, Mainz DT, Repasky MP, Knoll EH, Shelley M, Perry JK, Shaw DE, Francis P, Shenkin PS. Glide: a new approach for rapid, accurate docking and scoring. 1. Method and assessment of docking accuracy. J Med Chem 2004; 47: 1739-1749

126 Jones G, Willett P, Glen RC, Leach AR, Taylor R. Development and validation of a genetic algorithm for flexible docking. J Mol Biol 1997; 267: 727-748

127 Jain AN. Surflex: fully automatic flexible molecular docking using a molecular similarity-based search engine. J Med Chem 2003; 46: 499-511

128 Li Y, Han L, Liu Z, Wang R. Comparative assessment of scoring functions on an updated benchmark: 2. Evaluation methods and general results. J Chem Inf Model 2014; 54: 1717-1736

129 Bissantz C, Folkers G, Rognan D. Protein-based virtual screening of chemical databases. 1. Evaluation of different docking/scoring combinations. J Med Chem 2000; 43: 4759-4767

130 Bar-Haim S, Aharon A, Ben-Moshe T, Marantz Y, Senderowitz H. SeleX-CS: a new consensus scoring algorithm for hit discovery and lead optimization. J Chem Inf Model 2009; 49: 623-633

131 Teramoto $R$, Fukunishi $H$. Structure-based virtual screening with supervised consensus scoring: evaluation of pose prediction and enrichment factors. J Chem Inf Model 2008; 48: 747-754

132 Clark RD, Strizhev A, Leonard JM, Blake JF, Matthew JB. Consensus scoring for ligand/protein interactions. J Mol Graph Model 2002; 20: 281295

133 Charifson PS, Corkery JJ, Murcko MA, Walters WP. Consensus scoring: A method for obtaining improved hit rates from docking databases of three-dimensional structures into proteins. J Med Chem 1999; 42: 5100-5109

134 Feher $M$. Consensus scoring for protein-ligand interactions. Drug Discov Today 2006; 11: 421-428

135 Plewczynski D, Łaźniewski M, von Grotthuss M, Rychlewski L, Ginalski $K$. VoteDock: consensus docking method for prediction of protein-ligand interactions. J Comput Chem 2011; 32: 568-581

136 Houston DR, Walkinshaw MD. Consensus docking: improving the reliability of docking in a virtual screening context. J Chem Inf Model 2013; 53: 384-390

137 Paul N, Rognan D. ConsDock: A new program for the consensus analysis of protein-ligand interactions. Proteins 2002; 47: 521-533

138 Scior T, Verhoff M, Gutierrez-Aztatzi I, Ammon HP, Laufer S, Werz O. Interference of boswellic acids with the ligand binding domain of the glucocorticoid receptor. J Chem Inf Model 2014; 54: 978-986

139 Peeters M, Li Q, Elands R, van Westen GJ, Lenselink EB, Müller CE, IJzerman AP. Domains for activation and inactivation in $G$ protein-coupled receptors-a mutational analysis of constitutive activity of the adenosine A2B receptor. Biochem Pharmacol 2014; 92: 348-357

140 Thiyagarajan V, Lin SH, Chia YC, Weng CF. A novel inhibitor, 16-hydroxy-cleroda-3,13-dien-16,15-olide, blocks the autophosphoryla- 
tion site of focal adhesion kinase (Y397) by molecular docking. Biochim Biophys Acta 2013; 1830: 4091-4101

141 Hussain A, Melville JL, Hirst JD. Molecular docking and QSAR of aplyronine $A$ and analogues: potent inhibitors of actin. J Comput Aided Mol Des 2010; 24: 1-15

142 Koukoulitsa C, Zervou M, Demetzos C, Mavromoustakos T. Comparative docking studies of labdane-type diterpenes with forskolin at the active site of adenylyl cyclase. Bioorg Med Chem 2008; 16: 8237-8243

143 http://ec.europa.eu/research/health/infectious-diseases/antimicrobial-drug-resistance/projectsfp7_en.html. Accessed June 22, 2014

144 http://www.nabativi.org/. Accessed September 26, 2013

145 Srinivas N, Jetter P, Ueberbacher BJ, Werneburg M, Zerbe K, Steinmann J, Van der Meijden B, Bernardini F, Lederer A, Dias RL, Misson PE, Henze H, Zumbrunn J, Gombert FO, Obrecht D, Hunziker P, Schauer S, Ziegler U, Käch A, Eberl L, Riedel K, DeMarco SJ, Robinson JA. Peptidomimetic antibiotics target outer-membrane biogenesis in Pseudomonas aeruginosa. Science 2010; 327: 1010-1013

146 Chan FY, Sun N, Neves MA, Lam PC, Chung WH, Wong LK, Chow HY, Ma DL, Chan PH, Leung YC, Chan TH, Abagyan R, Wong KY. Identification of a new class of FtsZ inhibitors by structure-based design and in vitro screening. J Chem Inf Model 2013; 53: 2131-2140

147 Huang KJ, Lin SH, Lin MR, Ku H, Szkaradek N, Marona H, Hsu A, Shiuan $D$. Xanthone derivatives could be potential antibiotics: virtual screening for the inhibitors of enzyme I of bacterial phosphoenolpyruvatedependent phosphotransferase system. J Antibiot (Tokyo) 2013; 66: 453-458

148 Harris SM, McFeeters H, Ogungbe IV, Cruz-Vera LR, Setzer WN, Jackes $B R$, McFeeters RL. Peptidyl-tRNA hydrolase screening combined with molecular docking reveals the antibiotic potential of Syzygium johnsonii bark extract. Nat Prod Commun 2011; 6: 1421-1424

149 Kirchmair J, Distinto S, Liedl KR, Markt P, Rollinger JM, Schuster D, Spitzer GM, Wolber G. Development of anti-viral agents using molecular modeling and virtual screening techniques. Infect Disord Drug Targets 2011; 11: 64-93

150 Srinivasan S, Sarada DV. Antifungal activity of phenyl derivative of pyranocoumarin from Psoralea corylifolia L. seeds by inhibition of acetylation activity of trichothecene 3-0-acetyltransferase (Tri101). J Biomed Biotechnol 2012; 2012: e310850

151 Singh C, Atri N. Chemo-informatic design of antibiotic geldenamycin analogs to target stress proteins HSP90 of pathogenic protozoan parasites. Bioinformation 2013; 9: 329-333

152 Chen YZ, Zhi DG. Ligand-protein inverse docking and its potential use in the computer search of protein targets of a small molecule. Proteins 2001; 43: 217-226

153 Vigers GP, Rizzi JP. Multiple active site corrections for docking and virtual screening. J Med Chem 2004; 47: 80-89

154 Paul N, Kellenberger E, Bret G, Müller P, Rognan D. Recovering the true targets of specific ligands by virtual screening of the protein data bank. Proteins 2004; 54: 671-680

155 Berman HM, Westbrook J, Feng Z, Gilliland G, Bhat TN, Weissig H, Shindyalov IN, Bourne PE. The Protein Data Bank. Nucleic Acids Res 2000; 28: $235-242$

156 Schomburg I, Chang A, Ebeling C, Gremse M, Heldt C, Huhn G, Schomburg $D$. BRENDA, the enzyme database: updates and major new developments. Nucleic Acids Res 2004; 32: D431-D433

157 Chen X, Ji ZL, Chen YZ. TTD: therapeutic target database. Nucleic Acids Res 2002; 30: 412-415

158 Gao Z, Li H, Zhang H, Liu X, Kang L, Luo X, Zhu W, Chen K, Wang X, Jiang $H$. PDTD: a web-accessible protein database for drug target identification. BMC Bioinf 2008; 9: e104

159 Kellenberger E, Muller P, Schalon C, Bret G, Foata N, Rognan D. sc-PDB: an annotated database of druggable binding sites from the Protein Data Bank. J Chem Inf Model 2006; 46: 717-727

160 Wishart DS, Knox C, Guo AC, Cheng D, Shrivastava S, Tzur D, Gautam B, Hassanali $M$. DrugBank: a knowledgebase for drugs, drug actions and drug targets. Nucleic Acids Res 2008; 36: 901-906

161 Do QT, Bernard P. Pharmacognosy and reverse pharmacognosy: a new concept for accelerating natural drug discovery. IDrugs 2004; 7: 1017-1027
162 Do QT, Renimel I, Andre P, Lugnier C, Muller CD, Bernard P. Reverse pharmacognosy: application of selnergy, a new tool for lead discovery. The example of epsilon-viniferin. Curr Drug Discov Technol 2005; 2: 161-167

163 Do QT, Lamy C, Renimel I, Sauvan N, André P, Himbert F, Morin-Allory L, Bernard $P$. Reverse pharmacognosy: identifying biological properties for plants by means of their molecule constituents: application to meranzin. Planta Med 2007; 73: 1235-1240

164 Rollinger JM. Accessing target information by virtual parallel screening-the impact on natural product research. Phytochem Lett 2009; 2: $53-58$

165 Chen SJ. A potential target of Tanshinone IIA for acute promyelocytic leukemia revealed by inverse docking and drug repurposing. Asian Pac J Cancer Prev 2014; 15: 4301-4305

166 Chen YZ, Ung CY. Prediction of potential toxicity and side effect protein targets of a small molecule by a ligand-protein inverse docking approach. J Mol Graph Model 2001; 20: 199-218

167 Schomburg KT, Bietz S, Briem H, Henzler AM, Urbaczek S, Rarey M. Facing the challenges of structure-based target prediction by inverse virtual screening. J Chem Inf Model 2014; 54: 1676-1686

168 Grinter SZ, Liang Y, Huang SY, Hyder SM, Zou X. An inverse docking approach for identifying new potential anti-cancer targets. J Mol Graph Model 2011; 29: 795-799

169 Li H, Gao Z, Kang L, Zhang H, Yang K, Yu K, Luo X, Zhu W, Chen K, Shen J, Wang $X$, Jiang $H$. TarFisDock: a web server for identifying drug targets with docking approach. Nucleic Acids Res 2006; 34: W219-W224

170 Hui-fang L, Qing S, Jian Z, Wei F. Evaluation of various inverse docking schemes in multiple targets identification. J Mol Graph Model 2010; 29: 326-330

171 Nicola G, Liu T, Gilson MK. Public domain databases for medicinal chemistry. J Med Chem 2012; 55: 6987-7002

172 Wale N, Karypis G. Target fishing for chemical compounds using target-ligand activity data and ranking based methods. J Chem Inf Model 2009; 49: 2190-2201

173 Pandini A, Fraccalvieri D, Bonati L. Artificial neural networks for efficient clustering of conformational ensembles and their potential for medicinal chemistry. Curr Top Med Chem 2013; 13: 642-651

174 Rognan $D$. Structure-based approaches to target fishing and ligand profiling. Mol Inf 2010; 29: 176-187

175 Wermuth G, Ganellin CR, Lindberg P, Mitscher LA. Glossary of terms used in medicinal chemistry (IUPAC Recommendations 1998). Pure Appl Chem 1998; 70: 1129-1143

176 Nettles JH, Jenkins JL, Bender A, Deng Z, Davies JW, Glick M. Bridging chemical and biological space: "target fishing" using 2D and 3D molecular descriptors. J Med Chem 2006; 49: 6802-6810

177 Todeschini R, Lasagni M, Marengo E. New molecular descriptors for 2D and 3D structures. Theory. J Chemometr 1994; 8: 263-272

178 Bravi G, Gancia E, Mascagni P, Pegna M, Todeschini R, Zaliani A. MSWHIM, new 3D theoretical descriptors derived from molecular surface properties: a comparative 3D QSAR study in a series of steroids. J Comput Aided Mol Des 1997; 11: 79-92

179 Medina-Franco JL, Martínez-Mayorga K, Bender A, Marín RM, Giulianotti MA, Pinilla C, Houghten RA. Characterization of activity landscapes using 2D and 3D similarity methods: consensus activity cliffs. J Chem Inf Model 2009; 49: 477-491

180 Bauer MR, Ibrahim TM, Vogel SM, Boeckler FM. Evaluation and optimization of virtual screening workflows with DEKOIS 2.0 - a public library of challenging docking benchmark sets. J Chem Inf Model 2013; 53: 1447-1462

181 Bender A, Jenkins JL, Scheiber J, Sukuru SCK, Glick M, Davies JW. How similar are similarity searching methods? A principal component analysis of molecular descriptor space. J Chem Inf Model 2009; 49: 108-119

182 Scior T, Bernard P, Medina-Franco JL, Maggiora GM. Large compound databases for structure-activity relationships studies in drug discovery. Mini Rev Med Chem 2007; 7: 851-860 